\title{
IUS EST IDEM QUOD DOMINIUM: CONRADO SUMMENHART, FRANCISCO DE VITORIA Y LA CONQUISTA DE AMÉRICA
}

Jörg Alejandro Tellkamp*

RESUMEN-En este artículo se argumenta que la concepción que Francisco de Vitoria formula acerca de la Conquista de América se basa en nociones que provienen de varias fuentes de los siglos XIV y XV. Una de las más importantes es el Opus septipertitum de contractibus del teólogo alemán Conrado Summenhart a quien Vitoria cita con frecuencia. Al contrastar ambos autores se pone en evidencia que la bases terminológicas para asir los problemas relacionados con el derecho a la propiedad, el dominio, surge en buena parte del debate del maestro salmantino con Summenhart. PALABRAS CLAVE - Dominio. Francisco de Vitoria. Conrado Summenhart.
ABSTRACT - This article intends to argue that Francisco de Vitoria's conception of the Spanish Conquest of America is based upon notions that stem from various sources of the 14th and 15th Century. One of his most important source is the Opus septipertitum de contractibus, written by the German theologian Conradus Summenhart, whom Vitoria quotes frequently. By comparing both thinkers it can be shown that Vitoria's basic terminology concerning rights and dominion is in greatly indebted to Summenhart's account.

KEY WORDS - Dominion. Francisco de Vitoria. Conradus Summenhart.

\section{Aproximación}

Francisco de Vitoria (c. 1485-1546) no sólo es el spiritus rector, sino que es sin duda el pensador más conocido de la así llamada Escuela de Salamanca. El pensamiento vitoriano ha sufrido una serie de interpretaciones que pretenden realzar su originalidad radical frente al problema jurídico y moral de la Conquista de América. Sin embargo, a diferencia de esta visión bienintencionada, pero fundamentalmente

* Departamento de Filosofía, Universidad Autónoma Metropolitana.

\begin{tabular}{|l|l|l|l|l|l|}
\hline VERITAS & Porto Alegre & v. 54 & n. 3 & set./dez. 2009 & p. 34-51 \\
\hline
\end{tabular}


sesgada, es imposible no tomar en cuenta el trasfondo teórico que históricamente condicionó al pensador salmantino. Tan sólo hay que pensar que su formación académica se llevó a cabo en la Universidad de París, en una época en que la teología se encontraba bajo la influencia tanto de la vía moderna como de la vía antigua. Sus años de formación coinciden temporalmente con la actividad de destacados teólogos como Juan Mair, Jacques Almain, pero también con la del Cardenal Caietano. ${ }^{1}$ En la obra vitoriana se puede constatar una influencia del conciliarismo de los siglos XIV y XV, pero también es palpable una fuerte presencia del pensamiento de Tomás de Aquino. Debido a la variedad de sus fuentes y su manera un tanto ecléctica de usarlas, se puede decir que sus posturas político-filosóficos son más que un estéril replanteamiento de teorías tomasianas; su obra es tanto fruto de la teología del siglo XIII como lo es de la de los siglos XIV y XV. ${ }^{2}$

En este artículo se hará énfasis en tres aspectos. (1) El primero es de orden histórico-filosófico. Consiste en trazar los lineamientos básicos de la teoría del dominio del teólogo alemán Conrado Summenhart (c.14581502). La razón de ello está en que Vitoria, sobre todo en su Comentario a la Secunda Secundae, frecuentemente recurre a la obra central de Summenhart, el Opus septipertitum de contractibus, para aclarar su propia noción de dominio. Esto es tanto más relevante por cuanto que recientemente se ha visto en la doctrina de Summenhart una forma prototípica de derechos subjetivos. ${ }^{3}$ (2) Por ello se analizará en segundo lugar la teoría del dominio de Vitoria, enfocando principalmente la cuestión 62 de su Comentario a la Secunda Secundae, donde establece las bases conceptuales para un teoría del dominio. (3) Finalmente se tratará de mostrar cómo Vitoria, en discusión crítica con Summenhart, llega a una concepción de dominio que le permitiría establecer los parámetros de justicia en la Conquista de América. De esta manera, el debate con la tradición se convierte en un catalizador del pensamiento vitoriano.

\section{Dominio, derecho y razón}

En el concepto de dominio (dominium) es posible rastrear el origen de los derechos individuales. Esto significa principalmente que, cuando alega el poder sobre un dominio, puede hacer efectivo un reclamo tanto desde el punto de vista moral como legal. Se trata de una forma primitiva

1 Sobre el contexto de la vida y obra de Francisco de Vitoria véase CARRO. 1951, p. 261ss.

2 Acerca del desarrollo del lenguaje de los derechos véase BRETT. 1997; sobre Summenhart en particular cf. p. 34-43.

3 VARKEMAA. 2005, p. 181. 
de derechos de propiedad, por cuanto permite distinguir lo que pertenece a $A$ de lo que pertenece a $B$. En la tradición de los siglos XIV y XV la noción de derecho es marcadamente activa; es un poder o una facultad respecto de algo. De esta manera el propietario, el dominus, puede ejercer su libre voluntad respecto de la cosa de la que es dueño, de manera que la pueda enajenar, prestar etc. ${ }^{4} \mathrm{Al}$ hacer esto se manifiesta como un ser racional dotado de libertad; ambos conceptos, racionalidad y libre voluntad, son producto del acto de creación divino, mediante el cual Dios hizo al ser humano a su imagen. (i) "Razón" es, pues, una facultad, con la que alguien puede resolver problemas matemáticos, reparar aparatos, etc. (ii) Asimismo, "razón" tiene un significado normativo, dado que no sólo apunta a las actividades racionales que un ser humano puede realizar, sino que también connota lo que es razonable. De esta manera construir una bomba es un acto racional, pero no es razonable hacerla, en cuanto que su empleo contradice una serie de parámetros. Para Summenhart al igual que para Vitoria este parámetro remite en últimas instancias a Dios. En lo que, cuando uso la expresión "criterio de racionalidad", me referiré a los dos significados de razón. Sin él no puede haber derechos ni dominios.

"Dominio" es una de las principales nociones en la incipiente reflexión teológica y filosófica acerca de la Conquista del continente americano. En "dominio" se concentran los análisis sobre lo que significa ser propietario de una cosa o ejercer poder político sobre una comunidad y un territorio. Es decir, ¿quién puede legítimamente ejercer el poder político sobre un determinado territorio y sus comunidades? Como se verá más adelante, Vitoria enmarca sus pensamiento acerca de la legitimidad de reclamos sobre las cosas materiales (territorios, caballos etc.) o inmateriales en lo que en su tiempo ya es el contexto tradicional de la discusión sobre la justicia conmutativa, es decir aquella noción de justicia que establece la equidad en las interacciones contractuales, comerciales etc. Sin embargo, Vitoria considera que su análisis es difícil:

No es, pues, fácil explicar qué es el dominio (dominium) si no vemos primero qué es el derecho (ius), para que sepamos si el dominio es lo mismo que el derecho o si se funda en el derecho, porque, como veréis, no hay dominio que no se funde en el derecho. El derecho, por ende, [...] no es otra cosa que aquello que es lícito o lo que por ley es lícito, es decir que derecho es lo que es lícito por las leyes (quod est licitum per leges). ${ }^{5}$

4 Respecto de la noción de derechos activos y pasivos véase TUCK. 1979, p. 5

5 FRANCISCO de Vitoria. Comentarios a la Secunda Secundae de Santo Tomás: Tomo III De iustitia qq. 57-66. Salamanca: Instituto de Cultura Hispánica, 1934. p 63s 
Desde luego no es novedoso decir que el ejercicio de un dominio esté estrechamente ligado con la adjudicación de un derecho dentro del marco de las leyes. Bártolo de Sassoferrato (1313-1357), por ejemplo, pregunta: “¿Qué es, por tanto, dominio? Respondo: es el derecho de disponer perfectamente sobre una cosa corpórea, a menos que la ley lo prohíba". ${ }^{6}$ Décadas después y poniendo el énfasis en el aspecto facultativo del derecho dice Juan Gerson (1363-1429) que "el derecho es una facultad o es el poder cercano que le corresponde a alguien de acuerdo con el dictamen de la razón". ${ }^{7}$

Estos autores destacan principalmente tres aspectos: (1) dominio es una forma de derecho, aunque, como hicieran caer en cuenta otros autores, no todo derecho es un dominio. (2) Ese derecho tiene rasgos activos; se trata de una potestad o facultad y (3) se encuentra en un orden normativo dado que tiene que responder a la pregunta acerca de su legitimidad.

\section{Conrado Summenhart}

Conrado Summenhart también se suscribe a esta caracterización de dominio y derecho, pero le da una coherencia sistemática que tanto Bártolo como Gerson carecen. Es posiblemente por eso que Vitoria lo usa como punto de referencia constante en su Comentario a Secunda Secundae cuestión 62 .

Afortunadamente se conocen algunos detalles acerca de la vida de Conrado Summenhart. ${ }^{8}$ Nace hacia el año 1458 en Calw y en 1472 inicia sus estudios de artes en la Universidad de Heidelberg. En 1478 obtiene el grado de Magister Artium en París y posteriormente se inscribe en la Universidad de Tubinga, fundada en 1477. A partir de 1483 se desempeña como magister regens en la Facultad de Artes. No contento con ello comienza a fungir en la Facultad de Teología como bachiller bíblico y en 1489 obtiene el título de doctor en teología, convirtiéndose en colega de Gabriel Biel, pero dedicado a enseñar la via antiqua. El año 1502 fallece víctima de la peste. Entre sus obras, que comprenden un comentario a la Física de Alberto Magno y varios tratados casuísticos de teología, por ejemplo sobre la simonía, destaca su gran tratado de teología moral Septipertitum opus de contractibus pro foro conscientie

6 BARTOLUS de Sassoferrato. Super primam partem digesti veteris. Venetiis: Baptista Tortis, 1520, p. 92rb: "Quid ergo est dominium? Responde; est ius de re corporali perfecte disponendi, nisi lege prohibeatur".

7 JUAN Gerson. Oeuvres complètes, vol. 6, L'ouevre ecclésiologique (253a-291). Paris/ Tournai/Rome/New York: Desclée et Cie, 1965, p. 141: “[...] Jus est facultas seu potestas propinqua conveniens alicui secundum dictamen rationis".

8 Véase FELD. 2004, p. IX-XIII. Para una discusión más detallada de la concepción del derecho y dominio en Summenhart véase Brett op. cit., VARKEMAA. 2006, p. 119-47. 
atque theologico. Esta monumental obra fue editada por primera el año 1500 y reeditada en $1515 .{ }^{9}$ Existe asimismo una edición publicada en Venecia en $1580 .{ }^{10}$ Se caracteriza no sólo por desarrollar una teoría económica articulada, sino también - siendo este el interés principal de este artículo - por sistematizar la noción de dominio. ${ }^{11}$ Veamos los puntos más importantes.

En primer lugar muestra Summenhart su convicción de que la definición de derecho (ius), tal como nos la da Gerson, es correcta. Afirma: "El derecho es un poder o facultad próximo que le corresponde a alguien de acuerdo con el dictamen de la razón". En seguida relaciona esta definición con la de dominio: "Dominio es, pues, el poder o facultad próximo para tomar cosas ajenas en su poder o uso legítimo de acuerdo con los derechos o las leyes razonablemente instituidas". ${ }^{12}$ Con estas dos formulaciones, Summenhart no solamente acepta el criterio de racionalidad, sino que también logra establecer una estrecha relación entre derecho y dominio, relación que, como se verá, derivará en identidad.

Para llegar a establecer esta identidad delimita conceptualmente la noción de ius. Afirma que ésta puede ser entendida de dos maneras. Una, en cuanto se identifica con el concepto de ley (lex), de manera que de ella se derivan preceptos en el orden del derecho objetivo. Así, ley o derecho puede remitir al derecho canónico o a las leyes civiles que, por ejemplo, establecen las relaciones de propiedad. La segunda manera de dar cuenta con "derecho" consiste en confirmar su carácter, en el sentido en que se trata de facultades o poderes que alguien puede reivindicar. El padre, por ejemplo, tiene un derecho respecto del hijo y, por eso, ejerce sobre él un dominio. Por eso concluye Summenhart que derecho entendido de esta manera es lo mismo que dominio, ya que tener un derecho sobre una cosa significa formaliter lo mismo que ejercer un dominio sobre ella. ${ }^{13}$

9 Como anota FELD, op. cit., p. XI, nota 14, no existe una edición de 1513 a la que aún hacen referencia algunos estudiosos. Esto se debe a una transcripción errónea del colofón de la edición de 1500.

10 CONRAD Summenhart, Tractatus de Contractibus licitis, atque illicitis. Venetiis: Iunta 1580. Dado que la edición de 1515, que he podido consultar, no cuenta con paginación, me referiré a la edición de Venecia.

11 Véase VARKEMAA. 2006, p. 120, nota 2.

12 SUMMENHART, op. cit., tractatus I, questio I, 1a: "Ius est potestas vel facultas propinqua conveniens alicui secundum dictamen recte rationis. Dominium autem est potestas vel facultas propinqua assumendi res alias in sui facultate vel usum licitum secundum iura vel leges rationabiliter institutas".

${ }^{13} \mathrm{Ib} .:$ " [...] Capiendo ius secundo modo est idem quod dominium, et vere et universaliter predicatur de dominio sic quod omne dominium est ius secundo modo. [...] Probatur dupiliciter. Primo quod aliquem esse dominium alicuius rei est formaliter eum habere ius in illa re vel in illam rem; igitur dominium est ius: tenet consequentia a coniugatis. Secundo probatur quod diffinitio iuris secundo modo capti convenit formaliter dominio [...]". 
Todo lo que se puede predicar de un derecho, también se puede predicar de un dominio. Esta identidad, sin embargo, tiene que ser matizada, dado que el concepto de dominio, a diferencia del de derecho, se establece como una relación - por ejemplo entre padre e hijo - en un sentido jerárquico; a diferencia del concepto de derecho, el concepto de dominio connota superioridad (superioritas). ${ }^{14}$ De esta manera las relaciones de dominio solamente adquieren sentido cuando dueño y dominado no se encuentran en el mismo orden ontológico. Un caso relevante de subordinación ontológica sería el de la propiedad: para poder ser dueño de algo, tanto en el sentido legal como moral, es (1) indispensable que el sujeto sea activamente racional, por ejemplo un adulto. Si bien es necesario ser racional para ejercer un dominio, no es suficiente. Por ello, para que razonablemente se pueda hablar de dominios es (2) necesario tomar en cuenta el aspecto jerárquico mencionado. Entre sujetos que pertenecen a un mismo orden ontológico, por ejemplo un padre y otro padre, no puede haber una subordinación de dominio.

Las relaciones jerárquicas explican la existencia de dominios, pero no excluyen que el correlato inferior no posea derechos. Así, por ejemplo, el hijo puede tener un derecho sobre el padre, pudiendo reclamar los medios de sustento necesarios para vivir, no obstante, no por ello se convierte en su señor o dueño. Sólo en la relación inversa, de padre a hijo, la relación de derechos es también una relación de dominio: el padre es señor del hijo. De esta manera vemos que, al menos en el ámbito del derecho civil, la noción de dominio tiene menor amplitud que la de derecho. ${ }^{15}$

Summenhart sostiene una teoría activa de los derechos, en el sentido en que "cualquiera tiene tanto derecho o dominio sobre una cosa como le es lícito ejercer una acción respecto de ella". ${ }^{16}$ Ya se ha visto que decir esto no es novedoso, ya que tanto Bártolo como Gerson habían definido el derecho como una facultad o poder para tomar algo siempre y cuando la ley no lo prohíba. Sin embargo, con ello Summenhart establece una correlación más fuerte entre derecho y dominio que en sus predecesores. En él, al igual que en Gerson, encontramos que el fundamento para identificar derecho y dominio es el mismo: la recta razón. Es decir no sólo es necesario asumir que el sujeto de un dominio sea racional, sino que también los parámetros normativos que lo rigen se den de acuerdo con un criterio de rectitud o, como dice Summenhart, de justicia primera,

14 Ib., 1b: "Nam appropiate capiendo dominium connotat ultra rationem iuris etiam superioritatem, eo quod dominus est relativum suppositionis".

15 Ib.: "Dominium etiam loquendo de civili dominio, esset minus commune quam ius, etiam de civili iure loquendo [...]".

$16 \mathrm{Ib} ., 4 \mathrm{a}$. 
la cual se da en concordancia con la recta razón (recta ratio). Especifica que la recta razón puede ser entendida de dos maneras:

'Recta razón' se toma por aquella recta razón que desde el principio es original y esencialmente recta, y en este caso es lo mismo que la justicia primera [...]; también se entiende 'recta razón' de manera general en relación con la razón recta o bien que se trate esencialmente de la recta razón que existe sólo en Dios, o bien cómo se una por participación en las criaturas racionales. ${ }^{17}$

Al parecer Summenhart opta por el modelo participativo de la recta razón. Dios, como origen de la creación, ejerce sobre ella dominio, en el sentido de poder disponer sobre ella plenamente. Dado que Dios racional en un sentido máximo, dispone por ello del criterio necesario para determinar la rectitud de tal dominio. Lo que Dios determina, es de suyo justo y recto, porque así lo dispuso. ${ }^{18} \mathrm{En}$ el orden de la realidad creada, los seres humanos se aproximan a Dios, porque él mismo los creó a su imagen, con el resultado de que el género humano no sólo sea racional, aunque de manera disminuida, sino que también participe de ese orden racional; con ello "razón" adquiere un significado normativo (recta ratio). Cuando la recta razón se manifiesta en la razón humana, aquello que surge de ella, se llama ley natural y entre los asuntos que esta ley regula se encuentran las relaciones de propiedad que se generaron como resultado de la caída. ${ }^{19}$

Con miras a la lectura que Vitoria hace de Summenhart, la consecuencia principal en el ámbito de las interacciones humanas, que abarcan tanto el dominio como el derecho, es la siguiente. Si en el orden de la creación cada ser humano se constituye por participación en el dominio divino como dueño de algo o de alguien, entonces cumple el requisito mínimo de racionalidad. Que el ser humano racional pueda ejercer un dominio, sin embargo, no se identifica con que éste se ejerza de manera justa o recta, como construir una bomba. Si bien el dominio puede ser usado por alguien de manera desproporcionada o injusta, no puede por eso

17 Ib., $1 \mathrm{~b}$.

18 22b: "[...] Dominium conveniens Deo in creaturas convenit ei secundum dictamen rectae rationis. Recta enim ratio dictat, quod Deus debeat habere facultatem assumendi res creatas secundum suam volitionem, quae est prima iustitia, et quae est dictamen rectae rationis. Non tamen sic intelligendo, quod Deus alicui legi superiori subsit, sibi concedenti illud dominium, sed illud inexistens sibi dominium lex naturae approbat et dictat sibi debere convenire, non secundus, non tertius, quia dominia creaturarum irrationabilium, insensibilium, et demonum reducuntur ad secundum membrum, quia ratione donorum naturalium eis conveniunt".

19 Ib., 35b.: "Quod recta ratio naturalis in lumine suo naturali dictat: hoc est lex naturalis. Sed recta ratio dictat hoc complexum, scilicet hominibus pro statu naturae corruptae sunt res appropriandae et non reliquendae communes omnibus; igitur illud complexum est lex naturalis: sed illud complexum disponit distinctionem dominiorum; igitur distinctio dominiorum est a lege naturali". 
serle negado. ${ }^{20}$ En la Relectio de indis Vitoria haría uso extenso de esta distinción entre, para así decirlo, un dominio de hecho y un dominio justo para argumentar que los indígenas son verdaderos dueños de sus tierras, aún cuando ellos mismos vivan en pecado mortal.

\section{Francisco de Vitoria}

Para Vitoria, y de acuerdo con las Instituciones de Justiniano, el tema del dominio se inserta en la discusión sobre la justicia conmutativa (iustitia commutativa). El lugar donde esclarece lo relativo al concepto de dominio es la cuestión 62 de su Comentario a la Secunda Secundae que propiamente se dedica a la restitución, cuyo significado remite al restablecimiento de un dominio original. Por ello, a la pregunta si la restitución pertenece a la justicia conmutativa, y haciendo eco de Tomás de Aquino en la cuestión 62 artículo primero de la Secunda Secundae, responde lo siguiente:

Esto se demuestra por el significado de la palabra, porque restituir es devolver algo al dueño original. La restitución es volver a la igualdad, la cual corresponde a la justicia conmutativa, cuando se compensa una cosa por otra cosa. Por ello, si alguien me ha robado algo tengo menos de lo que debería tener y aquel [el ladrón] tendría más de lo que debería tener; por medio de la restitución se hace igualdad. ${ }^{21}$

Para poder analizar adecuadamente esta noción de restitución, cree Vitoria que es esencial primero aclarar los demás términos involucrados, sobre todo el de dominio, ya que para poder hablar de la justicia conmutativa que restablece la igualdad entre dos partes, es menester tener claridad sobre el fundamento en que se basa la propiedad (possessio). ${ }^{22}$ Adicionalmente, y en estrecha conexión con éste, es necesario dar cuenta con el concepto de derecho. Tal como lo hiciera Summenhart, parece suponer Vitoria que los dominios implican derechos y que derechos se identifican con dominios. Asimismo se apropia de la teoría de los derechos activos, tal como la encontramos en Summenhart. Esto quiere

20 Ib., 25b: "Civile dominium non fundatur in charitate sic, quod perdendo charitatem per lapsum in mortale cadat quis a dominio civili rerum suarum. [...] Civile dominium non perditur perdita charitate, quin remaneat essentialiter apud peccatorem [...]. Unde quamvis homo non possit esse iustus simpliciter sine charitate, potest tamen esse iustus dominus civiliter, vel politice. [...] Dominium civile acquiratur cum peccato, igitur".

21 VITORIA, op. cit., p. 61. Véase también DECKERS. 1991.

22 VITORIA, op. cit., p. 63: "Sed antequam materiam restitutionis aggrediamur, loquendum est de dominio, cum maxime hoc ad restitutionem conducat, quia possessio rei fundatur in dominio; quia quantumcumque aliquis caperet rem, si non haberet domin[i]um, non teneretur restituere. Et ideo aliqua sunt dicenda de dominio priusquam veniamus ad restitutionem". 
decir que los dominios son una facultad de ejercer un derecho sobre algo de acuerdo con los criterios de justicia y de la recta razón. Es aquí donde podemos constatar que Vitoria establece un diálogo crítico con el teólogo alemán. ${ }^{23}$

Para elucidar el concepto de dominio, la primera inquietud que trata de resolver Vitoria es curiosamente de índole lexicográfica: se pregunta si palabra dominium verdaderamente pertenece al vocabulario latino clásico o si únicamente es utilizada por los jurisconsultos y teólogos, en su mayoría medievales. ${ }^{24}$ Después de establecer que efectivamente se trata de un termino latino, dado que es empleado en las Instituciones de Justiniano, se apresta a esbozar el marco teórico del dominio, el cual depende de la noción de derecho. ${ }^{25}$ Vitoria anota enfáticamente que "no hay dominio que no esté fundado en el derecho". ${ }^{26} \mathrm{El}$ derecho, a su vez, se relaciona no sólo con el concepto de justicia, sino también con el de ley.

Siguiendo tanto a Bártolo, como a Gerson y Summenhart, pero en realidad también a Aristóteles y Tomás de Aquino, piensa Vitoria que el derecho (ius) siempre es también justicia (iustitia). La ley positiva, debido a su carácter público, tiene que ser reflejo de esa justicia. La ley se convierte en una condición de la justicia, porque apunta de manera ostensiva a lo que se debe hacer y lo que se debe omitir. ${ }^{27}$ Sólo la ley justa es ley y tiene eficacia únicamente cuando ha sido plasmada en un texto y cuando ha sido promulgada. En este sentido no es suficiente contar con que un cierto parámetro normativo sea justo, adicionalmente tiene que ser dado a conocer por medio de las leyes escritas. Sin embargo, Vitoria considera que hay que limitar esta aseveración, porque no cualquier instancia puede ser resuelta por medio de la legislación vigente, como es el caso de la Conquista de América, en que los indígenas se hacen acreedores de derechos y dominios. ${ }^{28}$ Ahora bien, para poder apreciar

${ }^{23}$ Ibid., p. 67: "Tertio modo capitur dominium largius prout dicit facultatem quamdam ad utendum re aliqua secundum jura, etc., sicut diffinit Conradus q. $t$ De contractibus [tr. 1], ubi dicit quod dominium est facultas utendi re secundum jura vel leges rationabiliter institutas. Et isto modo, si sic diffiniatur large capiendo, idem erit jus et dominium".

$24 \mathrm{Ib}$.

25 Ib., p. 63: "Sed de re ipsa jam dicendum est, scilicet quid sit dominum. Sed prius praemittendum est quid sit jus, nam dominium dependet a jure".

26 Ib., p. 63s.

27 Ib., p. 64: "Item, patet in eodem loco in corpore articuli, ubi dicit quod jus et justum idem sunt, teste Aristotele 5 Ethicorum; et justum illud idem est quod legibus licet: ergo jus etiam idem est, id est quod legibus licet. Dicit ergo quod jus est illud quod licitum est per leges. Et ita nos utimur illo vocabulo cum loquimur. Dicimus enim: non habeo jus facien[d]i hoc, id est non mihi licet; item, jure meo utor, id est licet".

${ }^{28}$ Esto se ve con especial claridad en el corolario ib., p. 82s. 
adecuadamente cómo los conceptos de derecho y dominio conducen a una valoración crítica de la Conquista hay que enfocarse en el significado de estos términos. Así, el maestro salmantino distingue tres significados de dominio:

1. El dominio puede ser entendido "estricta y peculiarmente" (stricte et peculiariter), lo que significa que la superioridad de alguien respecto de una cosa o de otras personas justifica que éste pueda ejercer un dominio. De esta manera es el príncipe señor de sus súbditos, porque ellos se encuentran en una relación jerárquica inferior respecto de él..$^{29}$ En este sentido estricto de dominio se dice también que Dios es señor de los seres humanos. En el ámbito de las interacciones humanas, tanto políticas como comerciales, se manifiesta esta superioridad en que el dueño o señor tiene sobre sus súbditos poder coactivo (potestas coercendi subditos). No obstante, el dominio del príncipe para ejercer el poder coactivo es más amplio que el derecho, ya que, como ilustra Vitoria con un ejemplo, la esposa tiene derechos respecto del marido, pero no es su dueña. ${ }^{30} \mathrm{Si}$ esto es así, entonces no cualquier dominio se identifica con un derecho.

2. El concepto de dominium también se puede entender en un sentido meramente jurídico, tal como lo encontramos en el Corpus iuris civilis y donde se distinguen de las nociones de uso, usufructo y posesión. ${ }^{31}$ El dominio comparte, por ejemplo, con el usufructo la característica de contener ciertos derechos, sin embargo, estos derechos no se identifican con el dominio, ya que así el usufructuario de una huerta se convertiría en su dueño por el simple hecho se ejercer el derecho a cultivarla.

3. Por último, y tomando como punto de referencia a Summenhart, introduce Vitoria una acepción de dominio que se origina en su tradicional definición como "facultad de usar una cosa de acuerdo con los derechos o las leyes razonablemente instituidas". ${ }^{32}$ Esta definición tiene la función de apartarse de la concepción meramente jurídica del dominio e introducirla en un contexto más que nada de valoración moral. Así, si a alguien se le niega el derecho de usar una cosa, literalmente la facultad de usarla, hay que proceder a la restitución de esa

${ }^{29}$ Ib., p. 65: "Uno modo, stricte et peculiariter ut dicit eminentiam quamdam et superioritatem, eo modo quo principes vocantur domini. Et sic alii homines vocantur domini respectu subditorum".

$30 \mathrm{Ib}$.

31 Ib., p. 66.

${ }^{32}$ Ib., p. 67. 
facultad. ${ }^{33} \mathrm{Si}$ se entiende el dominio como la facultad de tomar algo para uso propio, siempre y cuando esto ocurra de acuerdo con las leyes razonablemente establecidas, entonces la contravención a esta facultad deriva en una injuria (iniuria), la cual es la negación de un derecho (ius). Por eso, la injuria no solamente niega un derecho, sino que, al mismo tiempo niega el dominio. La reacción adecuada a tal infracción consistiría en restituir el derecho o dominio, lo que significa que moralmente hablando "derecho y dominio se definen de la misma manera". ${ }^{34}$

\section{Conquista, derecho y dominio según Vitoria}

Esta tercera acepción de dominio es de especial importancia, porque es la que permitiría que Vitoria formulara su teoría de los justos títulos de la Conquista de América. Me detendré en este punto principalmente para mostrar que la "modernidad" de Vitoria al cuestionar en la celebérrima Relectio de indis ciertos títulos de dominio - por ejemplo que el Papa o el Emperador sean dueños del orbe - es inconcebible sin las bases teóricas que establecen autores como Conrado Summenhart.

Vitoria profesa la convicción que el criterio de racionalidad, es decir que el dominio necesariamente requiera de la racionalidad de quien lo ejerce, es correcto. No solamente asume que cualquier ser humano es, debido a su constitución, un animal racional, sino que ningún ser humano puede ser tan desprovisto de capacidades racionales como para negar que el uso de las cosas es en sí lícito. ${ }^{35}$ Sin suponer la existencia de un ser dotado de razón no se puede decir que haya dominio en el sentido propia de la palabra. Por ello niega que los objetos inanimados y los animales sean depositarios de

33 Ib.: "Sed subdit Conradus, et bene, quod in materia de restitutione et morali potest capi dominium isto tertio modo et in hac significatione. Quia si tollimus aliquid $\mathrm{ab}$ aliquo habente dominium, isto modo tollimus facultatem ab illo utendi re, et ideo tenemur ad restitutionem. Quia ad boc quod ego tenear ad restitutionem, satis est quod faciam injuriam alicui in re ad quam ille babebat facultatem quamcumque; id est quaecumque esset illa facultas, si facio illi injuriam, teneor illi restituere. Et sic eodem modo diffinitur jus et dominium. Verum est quod est abusiva ista acceptio, non tamen ita quin ea saepe utamur in materia morali, ut dicit Conradus."

34 Ib.: "Et sic eodem modo diffinitur jus et dominium". También ib.: "Et in materia de restitutione indifferenter utemur dominio, scilicet sive sit dominus, sive usuarius, sive usufructuarius, si ve possessionarius, quia in eo etiam cadit injuria quae est obnoxia restitutioni."

35 Ib. p. 72: "Quo ergo jure hominibus convenit habere usum rerum? Dico quod jure naturali, quia est per se notum et a nullo unquam dubitatum, quia nulla fuit nec est gens tam barbara quae non credat esse licitum homini uti rebus: ergo est dominus illarum". 
derechos, lo cual permitiría adjudicarles un dominio. ${ }^{36}$ La razón para ello es simple:

Porque si los animales brutos tuvieran derecho y dominio respecto de sus actos, se les haría injuria. Así el sol tendría el derecho de iluminar y el cuervo de comer el cadáver. Si yo le cerrara la ventana al sol e impidiera que el cuervo comiera el cadáver, les haría injuria, lo cual es completamente falso, porque no son capaces de [recibir] injuria, por tanto tampoco [son capaces de tener] derechos. Efectivamente si se les hace injuria, no se les hace a ellos, sino a los hombres a quienes refieren, es decir sus dueños. Además, si pelean el toro y el león y si ambos tienen derechos, ¿quién recibe la injuria? O bien el león matando al toro, o bien el toro [matando] al león. ${ }^{37}$

También niega, como lo haría en la Relectio de indis, que el pecado o la herejía sean razones válidas para impedir que alguien pueda ejercer un dominio. ${ }^{38}$ La razón para ello está de nuevo en el criterio de racionalidad: si Dios hizo a todos los seres humanos a su imagen, entonces todos los seres humanos son imagen de la racionalidad divina y por lo tanto de suyo se encuentran en una relación de superioridad con cosas, animales etc. Además hay que recordar que para Vitoria el origen de la propiedad aquello que él llama la divisio rerum - es producto del pecado original. Adán pudo disponer de los bienes, y al contar con el consenso de la mayoría presumiblemente de Abel y Caín - pudo lícitamente repartirlos. ${ }^{39}$ El modelo del consenso es de especial importancia, porque en el plano de lo político le permite establecer la legitimidad del gobierno: sólo si la mayoría simple de los súbditos acepta a alguien como príncipe, puede este gobernar. Esto significa que la causa de la divisio rerum no solamente es resultado de la disolución del estado de gracia, sino que se basa en decisiones de los seres racionales para distinguir la legitimidad de ciertos derechos. Es más, este consenso, no tanto real, sino "virtuali et interpretativo", se convierte en el fundamento del derecho de gentes. ${ }^{40}$

${ }^{36}$ Cf. ib. p. 69s.

37 Ib., p. 71.

38 Ib., p. 74: "Homo per peccatum non perdidit illud dominium, sed adhuc est dominus omnium."

39 Ib., p. 78: "Primus est quod Adam fecit illam. Non quod fecerit illam in paradiso, quia Adam non fuit illic nisi per parvam morulam. Sed tamen post egressionem e paradiso, cum esset paterfamilias, potuit facere hanc rerum divisionem ex consensu filiorum, et divisit eis bona quae tunc erant prout visum est ei expedire. Itaque sive propria autoritate, sive ex consensu filiorum, potuit rerum divisionem facere dicendo: tu Abel habebis v. g. hos aureos, et tu Cain hos alios."

40 Ib., p.79: "Vel etiam possumus dicere quod potuit fieri divisio ex consensu virtuali et interpretativo occupando unusquisque suum locum, dimittendo loca aliorum. Et forte sic facta fuit, non consensu certo et formali, sed quodam consensu interpretativo, ita quod incoeperint aliqui colere certas terras et alius alias; et ex usu illarum rerum factum est ut ille esset contentus terris quas occupaverat, et alius aliis, ita quod unus non occupabat terras alterius. Et hoc non aliquo consensu formali, sed virtuali. Quia videbat unus alium habere illas terras, non curabat ire ad illas, sed capiebat alias. Et iste consensus sufficit ad jus gentium, quod [quia?] jus gentium certe ut plurimum constat solo isto consensu, scilicet virtuali." 
Esta aclaración es fundamental para resolver un asunto de extrema importancia: la querella de la Conquista de los territorios americanos, que algunos presumían sin dueño. Aquí la dificultad no es tanto pensar en que existen cosas que de suyo no tienen dueño, como las aves, los peces, los ríos y los mares, que cualquiera puede usar legítimamente. La diferencia entre el uso de una cosa pro libito y el ejercicio de un derecho, es decir dominio, sobre ella radica en que alguien ya pudo nombrar los títulos que lo legitiman. Pero, ¿cómo se da esta prima divisio et appropriatio? Para responder esta pregunta examina en la proposición 12 dos títulos que pueden justificar la adquisición de un dominio: ${ }^{41}$

1. El primer título proviene, como dice Vitoria, de la voluntad del dueño (voluntate possidentis), de manera que éste pueda transferir (translatio) su propiedad a quien quiera. Una excepción a esta transferencia voluntaria sería la necesidad vital, de manera que alguien pueda transitoriamente apropiarse de un bien, por ejemplo, ocupar una casa deshabitada para no morir de frío.

2. El segundo título proviene de la autoridad del gobernante (auctoritate principis) y pertenece, por eso, al ámbito del dominio político (dominium iurisdictionis).

Según Vitoria sólo estos dos títulos, la voluntad del dueño y la autoridad del gobernante, pueden justificar la adquisición de un dominio permanente bajo el supuesto de que se garanticen las condiciones de equidad que se dan en las transacciones y transferencias de dominio. Es de inmediato claro que el tema de la presencia española en el continente americano, forma parte de aquello que estas reflexiones intentan resolver. Ahora bien, los territorios americanos, al menos antes de la llegada de los españoles, no pertenecían a la esfera jurídica hispana. Por eso sugiere Vitoria que para resolver la transferencia de dominio - en el caso de la Conquista de tierras y poder político - no se pueden alegar razones provenientes del derecho positivo. Pero si solamente existiera el derecho natural como pauta, ¿a qué conclusiones podríamos llegar respecto de la justificación de la presencia de los españoles de estas tierras? ${ }^{42}$ Es aquí donde Vitoria comienza a desglosar los diferentes aspectos incluidos en el concepto de título (titulus).

En primer lugar constata el maestro salmantino que la transferencia de dominio de un dueño a otro ya se encuentra legitimado por el derecho natural (de iure naturali). Cualquier persona puede, mientras esto no contradiga las leyes positivas vigentes, enajenar sus propiedades. ${ }^{43}$

41 Ib., p. 81.

42 Ib., p. 82: "Sed circa istam propositionem duodecimam est dubium: an stando in solo jure naturali, et seclusa omni lege humana, possit fieri appropriatio rerum, id $43 \mathrm{Ib}$. est an quilibet possit transferre dominium suum in alium". 
Y esto significa que la razón de ser para el dominio y sus condiciones de transferencia y enajenación provienen principalmente de la relación natural que cada ser racional tiene con su propiedad y no tanto de las leyes positivas que reglamentan estas relaciones. Por ello es suficiente que el dueño tenga para sí mismo - en el fuero de la conciencia (in foro conscientiae) - la certeza de ser dueño una cosa. ${ }^{44}$ Vitoria ilustra esto con un ejemplo: la ganancia que una prostituta llega a obtener es de suyo legítima y no tiene que ser restituida al cliente, dado que se respetaron las condiciones para una transferencia de dominio, si se presume que él voluntariamente fue a buscarla, que fue dueño del dinero que pagó, que lo pagó voluntariamente, etc. ${ }^{45}$ En este caso es irrelevante que la prostitución sea moralmente y legalmente reprehensible. Este ejemplo es análogo a lo que Vitoria discute en la Relectio de indis, donde afirma que alguien, por estar en pecado mortal, no pierde su dominio, porque el pecado no guarda relación con lo que significa ser dueño (dominus), es decir ser racional, tener libre albedrío y la capacidad de realizar sus acciones. Por eso las relaciones de dominio y los títulos surgen de una dimensión interior: la racionalidad y la voluntad. De esta manera una regla objetiva, la de la ley positiva, y la acción públicamente observable, no sería condición necesaria para dar validez a la transferencia de un dominio. Es suficiente que las partes involucradas asientan tácitamente a la transferencia del dominio.

Aquí es significativo que Vitoria considere que ambos títulos, el de propiedad y el político, obtienen su justificación primaria in foro conscientiae. Es decir que tanto los criterios de la transmisión de dominios como la autoridad del gobernante respecto de sus súbditos por ejemplo, tomar la decisión respecto de sus vidas al enviarlos a una guerra - se derivan principalmente de normas que no pertenecen a la ley positiva. ${ }^{46}$ Sin embargo, lo dictaminado en el fuero de la conciencia también tiene que coincidir con la legislación vigente de una comunidad, siempre y cuando esas leyes sean en sí justas. Si esas leyes no fueran justas, entonces lo que se establece en el fuero de la conciencia no necesariamente incide en la legislación positiva y, a la inversa, ésta no invalida lo que se tiene por certero en la conciencia. Entonces, si se hace caso omiso del hecho de que la causa final de las leyes se manifiesta en

$44 \mathrm{Ib}$., p. 82s: "Potest enim quis in quem transfertur dominium tale esse tutus in conscientia. Et generaliter unus titulus ad formandum conscientias est iste, quod si quis verus dominus dat mihi aliquid quod non est lege prohibitum, ego sum vere dominus et non teneor ad restitutionem".

45 Ib., p. 83: "Unde sequitur quod quantumcumque quis sit prodigus, si daret mihi centum millia ducatorum, ego sum dominus, licet alius prodigaliter fecit, quia ille erat dominus et potuit pro arbitrio suo dare cui vellet. Etiamsi daret meretrici, illa esset vera domina et non teneretur ad restitutionem".

46 Ib., p. 86. 
su cumplimiento ritual y en ciertas condiciones, entonces no se sigue que habrá dárseles cumplimiento en el fuero de la conciencia. En otras palabras: lo que es válido in foro contentioso, no es necesariamente válido in foro conscientiae. ${ }^{47}$ No obstante, en la práctica, los parámetros válidos en la conciencia también deberían ser válidos ante un juez. ${ }^{48}$

Esto por lo visto significa que, cuando alguien cierra un contrato con el fin de transferir su propiedad, lo puede hacer primordialmente cuando tiene para sí la certeza de ser el propietario de la cosa en cuestión, aún cuando el asunto no sea igualmente claro ante una corte. Al establecer la relación entre lo que es válido in foro conscientiae y lo que es válido in foro contentioso es importante recalcar que para Vitoria el segundo se subordina estructuralmente al primero. Si un dominio no tiene certeza en la conciencia, entonces tampoco serán suficientes las leyes positivas para establecer su validez. Sin embargo hay que ver al dominio en el fuero contencioso como complementario: el dominio en el fuero de la conciencia sólo conduce a actos públicamente observables, como en el caso de herencias, contratos comerciales, si también existe una ley que razonablemente reglamenta este tipo de asuntos. La supremacía del fuero de la conciencia por encima de reglamentaciones legales también se hace palpable en la convicción vitoriana de la resolución de conflictos respecto de dominios es competencia principalmente del teólogo y no del jurista. Mientras el jurista no puedo sino seguir el texto establecido de las leyes, le es permitido al teólogo recurrir a aquella instancia que es propia se su labor de cura espiritual: la conciencia. ${ }^{49}$ De hecho Vitoria considera en la Relectio de indis:

47 Ib., p. 91: "Ratio ejus est quia solemnitas juris inventa est ad obviandum fraudibus et dolis, id est causa finalis juris est ponere illas conditiones et solemnitates ad obviandum dolis et fraudibus. Sed seclusa hac causa finalis, leges non obligant in foro conscientiae. Ergo si non sit dolus nec fraus, sequitur quod licet contractus non sit validus in foro contentioso, quod est validus in foro conscientiae".

48 Ib., p. 92: "Unde ob securitatem conscientiae pono hanc regulam: quod ex quocumque contractu non datur et acquiritur jus in foro contentioso, nec etiam datur nec acquiritur in foro conscientiae. [...] Quod enim secundum leges tenet, secundum conscientiam etiam valet".

49 Ib.: "[...] Ut respondeamus istis juristis, dico quod quantumcumque major pars jurisconsultorum et canonistarum amplectatur opinionem Panormitani, nihil tamen refert, quia ipsi parum auctoritatis habent in hujusmodi re. Mittunt siquidem falcem in messem alienam, utpote temporalis tantum est et contentiosa eorum cura, nihilque ad eos expectat judicare de foro conscientiae, sed de contentioso, bene tamen ad theologos. Quamobrem potius in hoc standum est dictis theologorum quam jurisconsultorum, quandoquidem theologi jus naturale divinumque norunt. Si tamen jusrisconsulti conscientiarum velint disserere casus, id tantum secundum eorum scripta jura eis conceditur. Quod enim secundum leges tenet, secundum conscientiam etiam valet. Quo fit ut theologis haesitantibus de aliquo quid juris sit in foro conscientiae, quia non inveniunt quid juris secundum leges scriptas sit propter legum intricationem, consulendi sunt juristae; non ut disserant quid juris in foro conscientiae sit, sed quid secundum leges scriptas sit verum ad tenendum, quidve leges ipsae disponunt ipsi diffiniant. Nam si hoc diffiniant, vere absque formidine inferet theologus quod etiam illud tenet in foro conscientiae". 
Afirmo, en segundo lugar, que esta discusión no pertenece a los juristas, o al menos no a ellos en exclusiva. Porque aquellos bárbaros no estaban sometidos, como diré en seguida, al derecho humano, y por tanto sus cosas no se han de examinar por leyes humanas sino divinas, en las cuales los juristas no son lo bastante competentes para poder definir por sí mismos semejantes cuestiones. $Y$ tratándose del fuero de la conciencia, es competencia de los sacerdotes, esto es, de la Iglesia, dilucidar el caso. Por esto, en el Deuteronomio (Dt 17,18) se manda que el rey reciba un ejemplar de la ley de mano del sacerdote. Y no sé con certeza que alguna vez hayan sido llamados para discutir y dilucidar esta cuestión teólogos que pudieran dignamente ser oídos sobre materia de tal importancia. ${ }^{50}$

La primacía del conocimiento teológico y, por ende, de aquello que pertenece al fuero de la conciencia, se relaciona tanto en el Comentario a la Secunda Secundae como en la Relectio de indis con el tema del poder político o, de acuerdo con la terminología de la época, con el dominio de jurisdicción (dominium iurisdictionis). Dado que la noción de dominación política depende conceptualmente de la caracterización de dominio como propiedad, se puede concluir que la justificación del poder político pertenece al ámbito de un análisis de la justicia conmutativa, lo cual explicaría cómo un determinado territorio pueda ser dominado por alguien distinto al dueño legítimo. De ahí que la pregunta que guía el tercer capítulo de la Relectio de indis es si hay "títulos legítimos por los cuales pudieron venir los indios a poder de los españoles". ${ }^{51}$

En principio la transferencia de dominación de un gobernante a otro se basa en la idea de tal transferencia se da en analogía con la transferencia del poder político que tiene su origen en Dios. Asimismo depende de que los súbditos voluntariamente se muestren en acuerdo con tal transferencia, dado que el gobernante debe representar sus intereses con miras al bien común. ${ }^{52}$

50 FRANCISCO de Vitoria. Relectio de indis, Carta Magna de los Indios. Madrid: CSIC, 1989, p. 61.

51 Ib., p. 99.

52 VITORIA, 1934, p. 86a: "Ex hoc sequitur responsio ad quaesitum et solutio ad argumentum supra positum. Responsio ergo est quod rex, qui habet auctoritatem a republica, potest ex justa causa rem alterius distribuere, id est potest transferre dominium ab uno in alium. Patet, quia omnis potestas a Domino Deo est; sed Deus potest transferre rem invito domino: ergo et princeps. Item, prima Petri 2 (v. 13) dicitur: Subjecti estote omni humanae creaturae, sive regi, etc., quia sic est voluntas Domini. Praeterea, princeps est electus a populo. Sed populus dat ei istam auctoritatem ut possit disponere de boni civium. Ergo potest disponere de bonis civis particularis, sicut ipsamet respublica potest, quia princeps habet in se consensum populi datum ut possit disponere de rebus reipublicae. Est enim jam consensus prioris domini, et leges etiam pendent a consensu reipublicae, licet rex eas instituat. Unde quod fecerit rex secundum leges, tenet factum, etiam invito domino, ut patet in subsidiis quae petit rex ab ecclesiasticis. Haec conclusio est Scoti in 4, d. 15 dicentis quod leges dant et adimunt jus in foro conscientiae. Idem dicit sanctus Thomas 1. 2, q. 96, a. 4. Et confirmat hoc Scotus, quia prima rerum divisio facta fuit auctoritate humana. Sed princeps habet hanc auctoritatem ex humana auctoritate. Ergo potest facere hanc divisionem". 
Sin embargo, cuando este asentimiento no se materializa, ¿cuál podría ser la razón para legitimar la transferencia del poder político? Para ello, de nuevo, es menester recurrir a la noción de título. Desde la perspectiva del teólogo, la legitimación de la transferencia de dominios políticos pertenece sobre todo al fuero de la conciencia. Recurrir a la conciencia, sin embargo, no significa recurrir a valoraciones de orden meramente subjetivo. El fuero de la conciencia más bien apunta a parámetros normativos objetivos que se derivan de un dictamen de la razón. Y en este sentido, juzgar y actuar de acuerdo con lo establecido en el fuero de la conciencia es objetivo.

Lo que se tiene por cierto en el fuero de la conciencia, como demuestran la reflexiones vitorianas en el Comentario a la Secunda Secundae, está por encima de las leyes positivas. En este sentido es posible establecer una relación entre la conciencia y aquello que se plasma en el derecho natural y, por ende, en el derecho de gentes. Hablando del derecho de ocupación de aquellos bienes que no tienen un propietario o dueño aparente, considera Vitoria que existe una razón válida para apropiarse de bienes: es el derecho de gentes (ius gentium), el cual posee un carácter coactivo, y por tanto parece ser la raíz de la ley positiva: "Obsérvese que si el derecho de gentes tiene en buena parte su origen en el derecho natural, claramente tiene fuerza para conceder derechos y crear obligaciones". ${ }^{53}$

Las anotaciones anteriores tuvieran la intención de mostrar que, con base en reflexiones hechas por Conrado Summenhart, Vitoria llega a formular una teoría de los derechos y del dominio con la que pretende mostrar que estos dos conceptos no dependen de otro criterio que el de racionalidad. Dado que la población indígena de América es racional, no es posible tomar sus propiedades a no ser que exista un título justo. Éste, sin embargo, sólo se daría en consecuencia de una injuria que los indígenas hubieran cometido a los españoles. Pero este sería tema de análisis detallado de las Relectiones De indis y De iure belli, que aquí no podemos hacer.

\section{Referencias}

BARTOLUS de Sassoferrato. Super primam partem digesti veteris. Venetiis: Baptista Tortis, 1520.

BRETT, A. Liberty, Right, and Nature: Individual Rights in Later Scholastic Thought. Cambridge: CUP, 1997

CARRO, V. La teología y los teólogos-juristas españoles ante la Conquista de América. Salamanca: Bibilioteca de Teólogos Españoles, segunda edición, 1951.

53 VITORIA, 1989, p. 102. 
CONRAD Summenhart. Tractatus de Contractibus licitis, atque illicitis. Venetiis: Iunta 1580.

DECKERS, D. Gerechtigkeit und Recht. Eine historisch-kritische Untersuchung der Gerechtigkeitslehre des Francsico de Vitoria (1483-1546). Freiburg i.Ue./Freiburg i.Br.: Universitätsverlag/Herder, 1991, 154ff.

FELD, H. Conradi Summenhart Opera Omnia, vol. 1: Tractatus theologici et canonistici. Mainz: Verlag Philipp von Zabern, 2004, p. IX-XIII.

FRANCISCO de Vitoria. Relectio de indis, Carta Magna de los Indios. Madrid: CSIC, 1989.

. Comentarios a la Secunda Secundae de Santo Tomás: Tomo III De iustitia qq. 57-66. Salamanca: Instituto de Cultura Hispánica, 1934.

JUAN Gerson. Oeuvres complètes, vol. 6, L'ouevre ecclésiologique (253a-291). Paris/ Tournai/Rome/New York: Desclée et Cie, 1965.

TUCK, R. Natural Rights Theories. Their Origin and Development. Cambridge: CUP, 1979.

VARKEMAA, J. "Summenhart's Theory of Rights: A Culmination of the Late Medieval Discourse on Individual Rights". In: MÄKINEN, V.; KORKMAN, P. Transformations in Medieval and Early-Modern Rights Discourse. Dordrecht: Springer, 2006, p. 119-47.

. "Justification through Being: Conrad Summenhart on Natural Rights". In: KRAYE, J.; SAARINEN, R. Moral Philosophy on the Threshold of Modernity. Dordrecht: Springer, 2005. 